\title{
PELATIHAN DENGAN METODE ROLE PLAY EFEKTIf TERHADAP KADER PMO-TB TENTANG PENEMUAN KASUS BARU TB PARU
}

\author{
Badar $^{1}$, Amiruddin ${ }^{2}$, Rizky Setiadi ${ }^{3}$, Gajali Rahman ${ }^{4}$ \\ 1)23)4) Jurusan Keperawatan, Poltekkes Kemenkes Kalimantan Timur \\ Email: badar.latif69@gmail.com
}

\begin{abstract}
Background: Indonesian TB cases are estimated 1,020,000, but the Ministry of Health (2017) reports only 420,000. The data case detection rate (CDR) health Office of Samarinda (2018), quarterly still fluctuations can be seen until the third quarter. Estimation of TB findings in Samarinda, (Bachtiar, R, 2018) year 2018 were, 3957 (39\%) people. The minimum achieved target were 1575 people. Data from the surveillance of Lempake health government clinic as of July 2018, TB cases were only found 30 cases of 720 suspects.

Objective: This study was analyzed the differences behavior of PMO-TB cadres before and after training in finding new cases of pulmonary TB with the role play method in the Lempake health government clinic working area of North Samarinda in 2018.

Method : This research was quasi-experiment, with the design of one group pretest-posttest. without a control group. The populations were all PMO TB cadres in the working area of Lempake government clinic were 30 people. The instrument used a questionnaire with variables knowledge, attitudes and actions of PMO-TB in finding new cases of pulmonary TB.

Results: Knowledge of PMO-TB after given role play training methods, became good as many as $22(73.3 \%)$, PMO-TB attitude after given role play method training, became positive as many as $16(53.3 \%)$, PMO Actions -TB after given the role play method training, became good as many as $18(60 \%)$.

Conclusion: There was significant improvement in knowledge, and attitudes, but not significantly in PMO-TB actions after the role play method training in the working area of North Samarinda Lempake health government clinic 2018.

Suggestion: It was expected that the government clinic of Lempake, especially the Pulmonary TB program holder, will increase the knowledge, attitudes and actions of pulmonary PMO-cadres in finding new cases of pulmonary $\mathrm{TB}$, using the role play method.
\end{abstract}

Keywords: TB, PMO, Knowledge, Attitude, Action, Role Play

\section{Abstrak}

Latar belakang : Kasus TB Indonesia diperkirakan ada 1.020.000, namun dilaporkan Kemenkes (2017) hanya 420.000 . Data Case Detection Rate (CDR) Dinas Kesehatan Kota Samarinda (2018), per triwulan yang masih mengalami fluktuasi yang dapat terlihat hingga triwulan ketiga. Estimasi penemuan TB di Samarinda, (Bachtiar, R, 2018) tahun 2018, yaitu, 3957 orang, ( $39 \%$ ) Target minimal harus dicapai adalah 
1575 orang. Data bagian surveilen Puskesmas Lempake Samarinda Utara per Juli 2018 ditemukan kasus TB hanya 30 kasus dari 720 suspek.

Tujuan : Tujuan penelitian ini menganalisis perbedaan perilaku kader PMO-TB sebelum dan setelah pelatihan penemuan kasus baru TB Paru dengan metode role play di wilayah kerja Puskesmas Lempake Samarinda Utara Tahun 2018.

Metode Penelitian ini menggunakan kuasi eksperimen, dengan rancangan one group pretest-posttest. tanpa kelompok control,dan telah melewati uji etik sebelum dilakukan eksperimen. Populasi seluruh kader PMO TB di wilayah kerja Puskesmas Lempake sebanyak 30 orang. Instrumen menggunakan kuesioner dengan variabel pengetahuan, sikap dan tindakan PMO-TB dalam menemukan kasus baru TB Paru.

Hasil : Pengetahuan PMO-TB sesudah diberikan pelatihan metode role play, menjadi baik sebanyak 22 orang $(73,3 \%)$, Sikap PMO-TB sesudah diberikan pelatihan metode role play, menjadi positif sebanyak 16 orang $(53,3 \%)$, Tindakan PMO-TB sesudah diberikan pelatihan metode role play, menjadi baik sebanyak 18 orang (60\%).

Simpulan : Ada peningkatan perbaikan signifikan pengetahuan, dan sikap, namun tidak signifikan pada tindakan PMO-TB setelah pelatihan metode role play di wilayah kerja Puskesmas Lempake Samarinda Utara 2018.

Saran : Diharapkan Puskesmas Lempake khususnya pemegang program TB Paru meningkatkan pengetahuan, sikap dan tindakan kader PMO-TB paru dalam menemukan kasus baru TB paru, menggunakan metode role play.

Kata Kunci : TB, PMO, Pengetahuan, Sikap, Tindakan, Role Play

\section{PENDAHULUAN}

Data WHO Global Tuberculosis Report 2016, Indonesia menempati posisi kedua dengan beban TB tertinggi di dunia. Tahun 2017. Diperkirakan ada 1.020.000 kasus di Indonesia, namun baru terlaporkan ke Kementerian Kesehatan sebanyak 420.000 kasus.

Riskesdas (2013) melaporkan penyebab kematian kedua semua umur setelah stroke adalah TB yaitu $75 \%$ masyarakat di dunia, termasuk Indonesia.

Menurut Direktur Jenderal Pencegahan dan Pengendalian Penyakit (Sugihartono,A. 2018) pada peringatan hari TB sedunia (21 Maret 2018) mengatakan bahwa penemuan kasus TB terus ditingkatkan secara intensif baik yang dilakukan fasilitas milik pemerintah maupun swasta, serta dilakukan juga penemuan aktif melalui pendekatan keluarga.

Kepala Dinas Kesehatan Provinsi Kalimantan Timur (Sukesi,R.R.,2017) mengatakan bahwa jumlah penemuan kasus baru TB tahan asam (BTA) positif meningkat, yaitu terdapat 2.391 kasus baru, Samarinda merupakan jumlah tertinggi yaitu 462 kasus dan terendah di Mahakam Hulu yaitu 30 kasus. Data Case Detection Rate (CDR) yang diperoleh dari DKK Samarinda tahun 2018, pada triwulan pertama sebesar $9,4 \%$, dan pada triwulan ke dua diperoleh angka $C D R$ sebesar $3,3 \%$, dan triwulan ke tiga sebesar $8,02 \%$. namun tahun 2018, angka per triwulan yang diperoleh masih mengalami 
fluktuasi yang dapat terlihat hingga triwulan ketiga. Estimasi target penemuan TB di Samarinda, (Bachtiar, $R, 2018$ ) pada tahun 2018, yaitu, 3957 orang, ( $39 \%$ ) Target program minimal yang harus dicapai adalah 1575 orang. Sementara itu, data yang diperoleh dari bagian surveilen Puskesmas Lempake Samarinda Utara per Juli 2018 ditemukan kasus TB yaitu hanya 30 kasus dari 720 suspek.

Dilain hal (Djedi Sj, 2016) mengatakan bahwa salah satu penyebab rendahnya penemuan kasus baru TB adalah belum melibatkan fasilitas pelayanan kesehatan pemerintah lainnya dan swasta. Dikuatkan oleh Kepala Dinas Kesehatan Propinsi Kalimanatan Timur, (Sukesi,R,2018) dalam rapat kerja kesehatan daerah (Rakerkesda) 2018,

\section{METODE PENELITIAN}

Penelitian ini menggunakan kuasi eksperimen, dengan rancangan one group pretest-posttest. Rancangan ini tidak ada control, tapi telah dilakukan observasi pertama (pre-test) yang memungkinkan peneliti dapat menguji perubahan yang terjadi setelah eksperimen (pelatihan), penemuan kasus baru dengan metode role play, dan telah melalui uji etik dengan no. I.B.02.01/7.1/6631/2018. Total sampel sebanyak 30 orang PMO-TB yang telah memenuhi kriteria yaitu kader PMO aktif, bersedia mengikuti kegiatan yang dilaksanakan dari awal sampai akhir, mengatakan bahwa dalam upaya percepatan eliminasi TB harus menciptakan sinergitas pemerintah pusat, propinsi dan kabupaten/ kota.

Berdasarkan penjabaran latar belakang diatas, maka penelitian ini di lakukan untuk menganalisis perbedaan perilaku kader sebelum dan setelah pelatihan penemuan kasus baru (CDR) TB Paru dengan metode role play di wilayah kerja Puskesmas Lempake Samarinda utara Tahun 2018. Tujuan penelitian ini adalah menganalisis perbedaan perilaku kader PMO-TB sebelum dan setelah pelatihan penemuan kasus baru TB Paru dengan metode role play di wilayah kerja Puskesmas Lempake Samarinda Utara Tahun 2018.

dan telah menandatangani informed consent. Variabel dependen penelitian adalah penemuan kasus baru TB paru, sedangkan variable independen adalah pengetahuan, sikap dan tindakan PMOTB paru. Instrumen Penelitian menggunakan angket dalam pengumpulan data. Teknik analisis data menggunakan uji Paired t-test yaitu membandingkan perbedaan dua nilai rata-rata yaitu sebelum pelatihan dan setelah pelatihan. Analisis menggunakan perangkat lunak pengolah statistik dan keputusan disesuaikan dengan taraf signifikansi 0,05 . 


\section{HASIL}

\section{Analisa Univariat}

Karakteristik Responden Penelitian

Gambaran karakteristik responden dapat dilihat pada tabel berikut ini:

Tabel 1 Distribusi Frekwensi berdasarkan Karakteristik responden di kelurahan Lempake tahun 2018

\begin{tabular}{ccc}
\hline Variabel & Frekuensi & Persentase \\
\hline Umur & 1 & \\
$18-24$ tahun & 2 & 3,3 \\
$25-31$ tahun & 6 & 6,7 \\
$32-38$ tahun & 7 & 20 \\
$39-45$ tahun & 12 & 23,3 \\
$46-52$ tahun & 2 & 40 \\
$53-59$ tahun & & 6,7 \\
\hline Jenis Kelamin & 0 & 0 \\
Laki-Laki & 30 & 100 \\
Perempuan & 5 & 16,7 \\
Pendidikan & 9 & 30 \\
SMP & 14 & 46,6 \\
SMA & & 6,7 \\
Perguruan Tinggi & 2 & 86,7 \\
(Diploma III, S1) & & 3,3 \\
Pekerjaan & 26 & 6,7 \\
Ibu Rumah Tangga & 1 & 3,3 \\
Petani & 2 & $\mathbf{1 0 0}$ \\
PNS & 1 &
\end{tabular}

Sumber: Data Primer 2018

Berdasarkan tabel 5.1. diperoleh bahwa sebagian besar responden berumur 46 - 52 tahun sebanyak 12 orang $(40 \%)$, semua responden berjenis kelamin perempuan sebanyak 30 orang $(100 \%)$ atau tidak ada responden lakilaki. Sebagian besar pendidikan responden SMA sebanyak 14 orang $(46,6 \%)$ dan yang terendah adalah pendidikan perguruan tinggi (diploma III, S1) sebanyak 2 orang $(6,7 \%)$. Sebagian besar responden adalah ibu rumah tangga sebanyak 26 orang $(86,7 \%)$ dan yang terendah adalah petani dan mahasiswa yang masing-masing sebanyak 1 orang $(3,3 \%)$. 


\section{Gambaran Pengetahuan tentang Penemuan Kasus Baru TB Paru}

Berikut ini merupakan hasil analisis univariat tingkat pengetahuan sebelum dan setelah diberikan pelatihan dengan metode roleplay:

Tabel 2 Distribusi Frekwensi Tingkat Pengetahuan Responden tentang Penemuan Kasus Baru TB Paru di kelurahan Lempake tahun 2018

\begin{tabular}{ccc}
\hline Pengetahuan & Frekuensi & Persentase (\%) \\
\hline Sebelum Pelatihan & & \\
Baik & 14 & 46,7 \\
Kurang & 16 & 53,3 \\
\hline Setelah Pelatihan & 22 & 73,3 \\
Baik & 8 & 26,7 \\
Kurang & $\mathbf{3 0}$ & $\mathbf{1 0 0}$ \\
\hline Total & &
\end{tabular}

Sumber: Data Primer 2018

Berdasarkan tabel 2, diperoleh hasil bahwa sebelum diberikan pelatihan dengan metode role play, sebagian besar responden berpengetahuan kurang baik sebanyak 16 orang $(53,3 \%)$, sedangkan responden berpengetahuan baik sebanyak 14 orang (46,7\%). Sesudah diberikan pelatihan dengan metode role play, sebagian besar responden pengetahuannya menjadi baik sebanyak 22 orang $(73,3 \%)$, sedangkan responden berpengetahuan kurang baik menjadi 8 orang

$(26,7 \%)$

\section{Gambaran Sikap tentang Penemuan Kasus Baru TB Paru}

Berikut ini merupakan hasil analisis univariat sikap responden sebelum dan setelah diberikan pelatihan dengan metode roleplay: 
Tabel 3 Distribusi Frekwensi Sikap Responden tentang Penemuan Kasus Baru TB Paru di kelurahan Lempake tahun 2018

\begin{tabular}{ccc}
\hline Sikap & Frekuensi & Persentase (\%) \\
\hline Sebelum Pelatihan & 10 & 33,3 \\
Positif & 20 & 66,7 \\
Negatif & 16 & 53,3 \\
\hline Setelah Pelatihan & 14 & 46,7 \\
Positif & $\mathbf{3 0}$ & $\mathbf{1 0 0}$ \\
Negatif &
\end{tabular}

Sumber: Data Primer 2018

Berdasarkan tabel 3, diperoleh hasil bahwa sebelum diberikan pelatihan dengan metode role play, sebagian besar responden bersikap negatif sebanyak 20 orang $(66,7 \%)$, sedangkan responden bersikappositif sebanyak 10 orang $(33,3 \%)$. Sikap sesudah diberikan pelatihan dengan metode role play, sebagian besar responden sikapnya positif sebanyak 16 orang $(53,3 \%)$, sedangkan responden bersikap negatif menjadi 14 orang $(46,7 \%)$.

\section{Gambaran Tindakan tentang Penemuan Kasus Baru TB Paru}

Berikut ini merupakan hasil analisis univariat tindakan responden sebelum dan setelah diberikan pelatihan dengan metode roleplay:

Tabel 4 Distribusi Frekwensi Tindakan Responden tentang Penemuan Kasus Baru TB Paru di kelurahan Lempake tahun 2018

\begin{tabular}{ccc}
\hline Tindakan & Frekuensi & Persentase (\%) \\
\hline Sebelum Pelatihan & 13 & 43,3 \\
Baik & 17 & 56,7 \\
\hline Setelah Pelatihan & 18 & 60 \\
Baik & 12 & 40 \\
Kurang & $\mathbf{3 0}$ & $\mathbf{1 0 0}$ \\
\hline Total & &
\end{tabular}

Sumber: Data Primer 2018

Berdasarkan tabel 4, diperoleh hasil bahwa sebelum diberikan pelatihan dengan metode role play, sebagian besar responden bertindak 
kurang baik sebanyak 17 orang $(56,7 \%)$, sedangkan responden bertindak baik sebanyak 14 orang $(43,3 \%)$. Sesudah diberikan pelatihan dengan metode role play, sebagian besar responden tindakannya menjadi baik sebanyak 18 orang $(60 \%)$, sedangkan responden bertindak kurang baik menjadi 12 orang (40\%).

di kelurahan Lempake dapat dilihat pada tabel berikut ini: sikap dan tindakan responden sebelum dan setelah pelatihan metode role play

Tabel 5 Analisis perbedaan pengetahuan, sikap, dan tindakan responden sebelum dan setelah pelatihan metode role play di kelurahan Lempake Tahun 2018

\begin{tabular}{ccc}
\hline Variabel & N & $\begin{array}{c}\text { P-Value } \\
\text { (Uji McNemar) }\end{array}$ \\
\hline $\begin{array}{c}\text { Pengetahuan Pretest dengan } \\
\text { Pengetahuan Posttest }\end{array}$ & 30 & 0,039 \\
\hline $\begin{array}{c}\text { Sikap Pretest dengan } \\
\text { Sikap Posttest }\end{array}$ & 30 & 0,016 \\
\hline $\begin{array}{c}\text { Tindakan Pretest dengan } \\
\text { tindakan Posttest }\end{array}$ & 30 & 0,063 \\
\hline
\end{tabular}

Sumber: Data Primer 2018

Hasil uji analisis bivariat pada tabel 5, diketahui hasil uji statistik Mc. Nemar yaitu $p$ value $=0,039$ dimana $p$ value $<0,05$, yang berarti hipotesis nol ditolak sehingga disimpulkan ada perbedaan secara signifikan antara pengetahuan responden sebelum dan setelah pelatihan metode role play di kelurahan Lempake.

Pada variabel Sikap didapatkan hasil uji statistik Mc.Nemar yaitu $p$ value $=0,016$ dimana $p$ value $<0,05$, yang berarti hipotesis nol ditolak sehingga disimpulkan ada perbedaan secara signifikan antara sikap responden sebelum dan setelah pelatihan metode role play di kelurahan Lempake.

Pada variabel tindakan, hasil uji statistik Mc. Nemar yaitu $p$ value $=0,063$ dimana $p$ value $<0,05$, yang berarti hipotesis nol diterima sehingga disimpulkan tidak ada perbedaan secara signifikan antara tindakan responden sebelum dan setelah pelatihan metode role play di kelurahan Lempake. 


\section{PEMBAHASAN}

\section{Analisa Univariat}

a. Pengetahuan

Berdasarkan hasil penelitian diperoleh bahwa sebelum diberikan pelatihan dengan metode role play, sebagian besar responden berpengetahuan kurang baik, yaitu 16 orang $(53,3 \%)$, dari 30 responden, terutama tidak mengetahui bahwa kuman TB dapat juga menyerang organ tubuh lain selain paru-paru misalnya tulang, persendian dan ginjal Hasil sesudah diberikan pelatihan dengan metode role play, sebagian besar pengetahuan responden baik, yaitu sebanyak 22 orang $(73,3 \%)$ dari 30 responden yang diteliti. Adanya peningkatan pengetahuan secara signifikan ini, peneliti berasumsi bahwa pelatihan dengan menggunakan metode role play berkorelasi positif dengan peningkatan pengetahuan, ini

b. Sikap

Berdasarkan hasil penelitian diperoleh bahwa sebelum diberikan pelatihan dengan metode role play, sebagian besar responden bersikap negatif, yaitu sebanyak 20 (66,7\%) responden. Pada questioner no. 1 responden setuju bahwa TB adalah penyakit yang sangat serius, dan pada questioner no. 10 responden sangat setuju bahwa penderita HIV lebih mudah tertular TB dibandingkan dengan orang yang bukan penderita HIV.

$$
\text { Hasil sesudah diberikan }
$$

pelatihan dengan metode role play, sebagian besar responden sikapnya disebabkan karena dengan role play responden dapat mengaktifkan panca indera, kognitif, skill atau keterampilan menjelaskan obyek, menggunakan materi yang telah dipelajari. Hasil penelitian ini sejalan dengan hasil penelitian oleh Widjanarko,B dkk, dalam riserchnya Analisis Faktor-Faktor Yang Mempengaruhi Praktik Pengawas Menelan Obat (PMO) Dalam Pengawasan Penderita Tuberkulosis Paru Di Kota Semarang mendukung teori Green,bahwa suatu perilaku akan dipengaruhi pula antara lain oleh faktor predisposisi seperti pengetahuan dari yang bersangkutan ( Green, 1991) Pengetahuan adalah merupakan hasil dari tahu, dan ini terjadi setelah orang melakukan penginderaan terhadap sesuatu objek tertentu. (Notoatmodjo, 2010).

menjadi positif yaitu $16 \quad(53,3 \%)$ responden. Sikap merupakan reaksi yang masih tertutup tidak dapat dilihat secara langsung sehingga sikap hanya dapat ditafsirkan dari perilaku yang tampak. Sikap bukan merupakan tindakan atau aktivitas akan tetapi adalah merupakan reaksi yang terbuka dan merupakan kesiapan untuk bereaksi terhadap objek lingkungan tertentu sebagai suatu penghayatan terhadap objek (Notoatmodjo, 2010).

\section{c. Tindakan}

Berdasarkan hasil penelitian diperoleh bahwa sebelum diberikan 
pelatihan dengan metode role play, sebagian besar responden bertindak kurang baik yaitu sebanyak 17 orang $(56,7 \%)$, terutama responden tidak mencatat dan tidak mengantar langsung ke pelayanan kesehatan (Puskesmas) setiap yang dicurigai sebagai penderita TB paru untuk pemeriksaan dahak Hasil sesudah diberikan pelatihan dengan metode role play, tindakan responden menjadi baik hanya bertambah 1 yaitu sebanyak 18 orang $(60 \%)$ atau tindakan responden tidak signifikan. Asumsi peneliti bahwa ketidak signifikannya tindakan responden ini diakibatkan kurang terpaparnya pelatihan, baik dari instansi pemerintah (Kemenkes) maupun swasta (PPTI), hal ini menyebabkan responden kurang termotivasi. Asumsi peneliti tersebut mengacu pada teori PrecedeProceed dari L. Green 1980, dalam Notoatmodjo (2010), yang mengatakan bahwa tindakan terbentuk dari 3 faktor, yakni : 1) Faktor Predisposisi (predisposing factors) Faktor yang mempermudah atau mempredisposisi terjadinya perilaku seseorang, antara lain pengetahuan, sikap, keyakinan, kepercayaan, nilai-nilai, tradisi, dan sebagainya.2) Faktor pemungkin (enabling factors) Faktor yang memungkinkan atau memasilitasi perilaku atau tindakan. Yang dimaksud pemungkin adalah sarana dan prasarana atau fasilitas, termasuk fasilitas pelatihan untuk terjadinya perilaku. 2) faktor penguat (reinforcing factors) Faktor yang mendorong atau memperkuat terjadinya perilaku. Dalam penelitian ini, meskipun para kader PMO-TB memiliki pengetahuan baik, sikap positif tetapi tidak ada dukungan dari pihak Puskesmas dalam hal ini bagian suvilence TB, dan PPTI berupa pelatihan maka perilaku atau tindakan PMO-TB tidak akan signifikan.

Menurut Notoatmodjo (2010), suatu sikap belum otomatis terwujud dalam suatu tindakan. Untuk mewujudkan sikap menjadi suatu perbuatan nyata diperlukan faktor pendukung atau suatu kondisi yang memungkinkan, antara lain adalah fasilitas, dan dukungan pihak lain,

\section{Analisa Bivariat}

a. Analisis perbedaan pengetahuan responden sebelum dan setelah pelatihan metode role play.

Berdasarkan hasil uji analisis bivariat diperoleh bahwa ada perbedaan secara signifikan antara pengetahuan responden sebelum dan setelah pelatihan metode role play di kelurahan Lempake $(p$ value $=0,039)$.

Proses belajar yang menumbuhkan sikap kritis dapat meningkatkan pengetahuan responden secara bermakna. Pengetahuan yang dimiliki PMO sebelum intervensi pelatihan metode role play masih kurang baik, kemudian setelah dilakukan pelatihan metode role play menjadi baik, hal tersebut membuat pengetahuan yang dimiliki PMO menjadi meningkat dan lebih bertahan lama sehingga dapat menjadi dasar perubahan sikap maupun tindakan. 
Green \& Keuter (2000) berpendapat bahwa proses belajar yang melibatkan peserta didik secara aktif akan menghasilkan pengetahuan yang lebih bertahan lama.

b. Analisis perbedaan sikap responden sebelum dan setelah pelatihan metode role play di kelurahan Lempake

Berdasarkan hasil uji analisis bivariat diperoleh bahwa ada perbedaan signifikan sikap sebelum dan setelah pelatihan metode role play di kelurahan Lempake $(p$ value $=0,016)$.

Proses perubahan sikap merupakan suatu hasil belajar yang dapat terjadi bila ada stimulus (pengetahuan) pada aspek kognitif seseorang (Azwar, 2007). Perubahan sikap sebelum dan sesudah intervensi menunjukkan bahwa dalam waktu yang relatif singkat kegiatan pelatihan metode role play dapat memberikan pengaruh terhadap perubahan sikap seseorang. Hal tersebut sesuai dengan prinsip

\section{SIMPULAN}

Hasil penelitian menunjukkan bahwa terdapat perbedaan pengetahuan dan sikap setelah diberikan pelatihan dengan metode roleplay, sedangkan pada tindakan, tidak terdapat perbedaan signifikan setelah diberikan pelatihan dengan metode roleplay. Perlu upaya peningkatan komunikasi terapeutik bagi PMO-TB terhadap pasien TB yang tertutup dan tidak kooperatif, pihak Puskesmas harus bisa metode role play yaitu menumbuhkan sikap kritis seseorang.

c. Analisis perbedaan tindakan responden sebelum dan setelah pelatihan metode role play $\mathrm{di}$ kelurahan Lempake

Berdasarkan hasil uji analisis bivariat diperoleh bahwa tidak ada perbedaan secara signifikan antara tindakan sebelum dan setelah pelatihan metode role play di kelurahan Lempake ( $p$ value $=0,063$ ).

Pengetahuan baik, sikap positif tidak berkorelasi secara signifikan dengan tindakan responden. Green dalam Notoatmodjo, (2010) mengemukakan bahwa tindakan individu desebabkan oleh 3 faktor terutama faktor reinforcing atau penguat. Menurut pernyataan pihak puskesmas kurang intens memberikan motivasi kepada PMO. Frekuensi pelatihan untuk PMO jarang dilakukan bahkan dalam satu tahun terakhir belum ada pelatihan baik dari Puskesmas maupun dari PPTI.

membangun jejaring dan kemitraan dengan PPTI dalam mengoptimalkan partisipasi PMO-TB dalam menemukan kasus baru TB Paru dan menyelenggarakan pelatihan dengan metode roleplay.

Kelemahan / Keterbatan Penelitian Kelemahan atau keterbatasan penelitian ini adalah pada desain penelitian yang menggunakan quasi 
experiment atau eksperimen semu yaitu menurut Arikunto, S.(2002) belum memenuhi keabsahan ilmiah. Lebih

DAFTAR PUSTAKA

Arikunto, S. (2002) Prosedur Penelitian, Suatu Pendekatan Praktek : Rineka Cipta

Anisah, IA. Dkk. (2017), Faktor-Faktor Yang Berhubungan Dengan

Keaktifan Kader Communty Tb Care 'Aisyiyah Surakarta, JURNAL KESEHATAN, ISSN 1979-7621, Vol. 10, No. 2, Desember 2017

Bachtiar, R, (2016) .Profil PPTI Samarinda., 2016. Data TB elektronik Tahun 2016.Samarinda.

Boy, E. (2015), Efektifitas Pelatihan Kader Kesehatan Dalam Penanganan

Tuberkulosis Di Wilayah Binaan, Vol. 4 | No. 2 | Juli 2015 | Jurnal Pendidikan Kedokteran Indonesia Hasibuan, Malayu S.P. (2005). Manajemen Sumber Daya Manusia. Jakarta: Bumi Aksara.

Djedi Sj,(2016) Kebijaksanaan Managemen Organisasi PPTI, Disampaikan pada acara pembekalan Cabang PPTI Kutai Timur,14 Desember 2016, Materi tidak dipublikasikan

Kemenkes RI. (2010). Buku Saku Petugas Kesehatan Di Puskesmas Untuk Pencegahan Pengendalian Infeksi TB . Jakarta: Kemenkes RI.

Kemenkes RI. (2011). Pedoman Pencegahan Dan Pengendalian TB Di Fasilitas Pelayanan Kesehatan. Jakarta: Kemenkes.

Kemenkes, RI. (2011). Rencana Aksi Nasional Public Private Mix Pengendalian TB

Kemenkes RI. (2013). Hasil Riskesdas 2013. http:// depkes.go.id. Di akses tanggal 13 Maret 2015. lemah karena rendahnya control terhadap subjek penelitian, (Putra, S.R, 2012)

Kemenkes RI. (2011). Pedoman Pencegahan Dan Pengendalian TB Di Fasilitas Pelayanan Kesehatan. Jakarta: Kemenkes.

Kemenkes, RI. (2011). Rencana Aksi Nasional Public Private Mix Pengendalian TB Indonesia 20112014. Jakarta: Kemenkes RI.

Kemenkes RI, (2015) Riskesdas. Machfoedz, Ircham. (2006). Statistik Deskriptif: Dengan Contoh-Contoh Kesehatan Masyarakat. Yogyakarta: Fitramaya.

Megawati, Dkk. (2018), Edukasi Tb Paru Pengetahuan Sikap Kader Posyandu Melalui Permainan Simulasi Monopoli, Media Publikasi Promosi Kesehatan Indonesia, The Indonesian Journal of Health Promotion

Nawawi, Hadari dan Martini, (2006). Instrumen Penelitian Bidang Sosial. Yogyakarta: Gajahmada University Press..

Notoadmojo, (2007).Promosi Kesehatan dan Ilmu Perilaku. Jakarta: RinekaCipta.

Nisa, SM, Dkk., Hubungan Antara Karakteristik Kader Kesehatan Dengan Praktik Penemuan Tersangka Kasus Tuberkulosis Paru, Journal of Health Education 2 (2017), http://journal.unnes.ac.id/sju/index. php/jhealthedu/diakses 19 Nov. 2018

Profil Kecamatan Lempake Tahun 2016. Priyanto, Agus. (2009). Komunikasi dan Konseling, Aplikasi dalam Sarana Pelayanan Kesehatan untuk Perawat dan Bidan. Jakarta: Salemba Medika. 
Putra, S.R, (2012) Panduan Riset Keperawatan dan Penulisan IImiah : D-Medika

Pratiwi,RD, Dkk. Peningkatan Kemampuan

Kader Kesehatan TB Dalam Active CaseFinding Untuk Mendukung Case Detection Rate, Journal of Health Education2(2)(2017),

http://journal.unnes.ac.id/sju/index.php/j healthedul, diakses 19 Nov.2018.

Sukesi,R.R.(2017)http://kaltim.prokal.co/ read/news/295398-naik-teruspenderita-tb-di-kaltim-capai-4358, diakses 19 Nov.2018

WHO.Global Tuberculosis Control WHO Report $2009 . \quad$ (Online) http://stoptb.org /DiaksesTanggal 02 Maret 2017

Wijaya, IMK, (2013), Pengetahuan, Sikap Dan Motivasi Terhadap Keaktifan Kader Dalam Pengendalian Tuberkulosis Jurnal Kesehatan Masyarakat, http://journal. unnes.ac.id/ nju/index.php/kemas, diakses 18 Nov. 2018

Wahyuni, CU \& Artanti, KD, (2013) Pelatihan Kader Kesehatan Untuk Penemuan Penderita Suspek Tuberkulosis, Jurnal Kesehatan Masyarakat Nasional Vol. 8, No. 2, September 2013

Widjanarko,B. dkk. Analisis Faktor-

Faktor Yang Mempengaruhi Praktik Pengawas Menelan Obat (PMO) Dalam Pengawasan WHO.Global Tuberculosis Control WHO Report 2009. (Online) http://stoptb.org /DiaksesTanggal 02 Maret 2017 